\title{
Lightning Induced Disturbances in Buried Cables-Part I: Theory
}

\author{
E. Petrache, Member, IEEE, F. Rachidi, Senior Member, IEEE, M. Paolone, C. A. Nucci, Senior Member, IEEE, \\ V. A. Rakov, Fellow, IEEE, and M. A. Uman, Fellow, IEEE
}

\begin{abstract}
In this paper, we present a review of theoretical methods to compute lightning induced currents and voltages on buried cables. The evaluation of such induced disturbances requires the calculation of the electric field produced by lightning along the cable path. We show that the Cooray's simplified formula is capable of predicting accurately the horizontal electric field penetrating the ground, at distances as close as $\mathbf{1 0 0} \mathrm{m}$. Regarding the parameters of the buried cable, a comparison of several approximations of the ground impedance is presented. We show that the Pollaczek expression corresponds to the Sunde general expression, when the displacement current is neglected. The analysis shows also that all the proposed approximations provide very similar results for the considered range of frequencies (up to $30 \mathrm{MHz}$ ). Most of the approximate formulas neglect the contribution of the displacement current and, therefore, predict values for the ground impedance which tend to infinity at higher frequencies. This corresponds in the time domain to a singularity of the ground transient resistance at $t=0$. By analogy to the Sunde approximation for the ground impedance of overhead lines, we propose a logarithmic approximation for the ground impedance of a buried cable. In addition, unlike most of the considered approximations, the proposed formula has an asymptotic behavior at high frequencies; therefore, the corresponding transient ground resistance in the time domain has no singularity at $t=0$. It is also demonstrated that within the frequency range of interest, the wire impedance can be neglected, due to its small contribution to the overall longitudinal impedance of the line. The ground admittance, however, can play an important role at high frequencies ( $1 \mathrm{MHz}$ or so) especially in the case of poor ground conductivity. The ground admittance needs to be taken into account in the calculation of lightning induced currents and voltages on buried cables. This is in contrast with the case of overhead lines in which its contribution is generally negligible, even in the MHz range.
\end{abstract}

We also investigate the time-domain representation of field-totransmission line coupling equations. The coupling model includes the effect of ground admittance which appears in terms of an additional convolution integral. An analytical expression for the ground transient resistance in the time domain is also proposed which is shown to be sufficiently accurate and nonsingular. Finally, we present a time domain solution of field-to-buried cable coupling equations using the point-centered finite difference time domain (FDTD) method, and a frequency domain solution using Green's functions. In our companion paper (Part II), we compare

Manuscript received October 20, 2004. This work was supported in part by Alcatel Submarine Network Division and by NSF Grant ATM-0346164.

E. Petrache is with the University of Toronto, Toronto, ON M5S 3G4, Canada (e-mail: emanuel.petrache@ieee.org).

F. Rachidi is with the Power Systems Laboratory, Swiss Federal Institute of Technology (EPFL), Lausanne, 1015 Switzerland (e-mail: farhad. rachidi@epfl.ch).

M. Paolone and C. A. Nucci are with the Department of Electrical Engineering, University of Bologna, Bologna, 40136 Italy (e-mail: mario. paolone@mail.ing.unibo.it; carloalberto.nucci@unibo.it).

V. A. Rakov and M. A. Uman are with the Department of Electrical and Computer Engineering, University of Florida, Gainesville, FL 32611-6200 USA (e-mail: rakov@ece.ufl.edu; uman@ece.ufl.edu).

Digital Object Identifier 10.1109/TEMC.2005.853161 both solutions to experimental waveforms obtained using triggered lightning.

Index Terms-Buried cables, electromagnetic coupling, lightning-induced voltages, modeling.

\section{INTRODUCTION}

O ENSITIVE electronic components have been increasingly used lately both in power and communication systems. These components, compared to the electromechanical ones used in the past, may suffer logic upset or damage at significantly lower levels of induced electromagnetic interferences. As a result, the evaluation of lightning induced disturbances on buried cables has recently attracted considerable attention (e.g., [1], [2]). Typical examples are submarine fiberoptic cables and buried telecommunication cables which include repeater power supply cables. Concerning submarine cables, long buried sections (up to $20 \mathrm{~km}$ ) are running from the shore to the supply units and are exposed to lightning threat.

The aim of this paper is to present efficient calculation methods to estimate lightning induced disturbances on buried cables in both time and frequency domains.

The paper is organized as follows: In Section II, we will consider the general expressions for the field penetrating in the ground [3] and we will discuss the approximate formula for the electric field below the ground surface recently proposed by Cooray [4]. In Sections III and IV, we will analyze the field-to-buried transmission line coupling equations in the frequency domains. In particular, we will discuss expressions proposed by different authors to describe the so-called ground impedance. The relative importance of line parameters for the case of buried cable is then analyzed in Section V. Time domain and frequency domain solutions of field-to-transmission line coupling equations will be presented in Sections VI and VII. Finally, a conclusion and recommendations will be given in Section VIII.

\section{LightNing RETURN STROKE ELECTRIC FIELD IN THE GROUND}

The determination of lightning induced currents and voltages in buried cables requires the knowledge of lightning return stroke electromagnetic field below the ground surface. Considering the lightning channel as a vertical antenna and the ground as a uniform half-space characterized by constant conductivity $\sigma_{g}$ and relative permittivity $\varepsilon_{r g}$, the general expressions in the frequency domain for the vertical $d E_{z}$ and horizontal $d E_{r}$ electric fields radiated by an elementary dipole located at height $z^{\prime}$ 


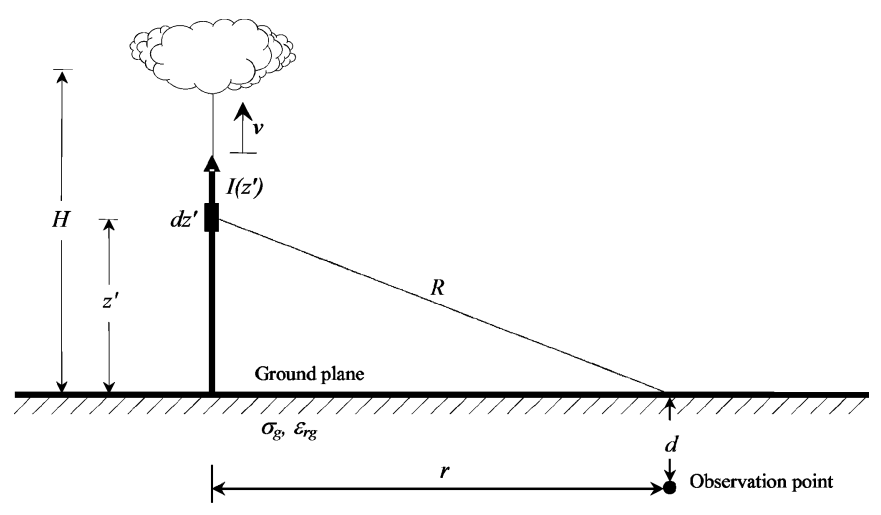

Fig. 1. Geometry for the calculation of electromagnetic field below the ground surface radiated by a vertical lightning channel.

above ground at a distance $r$ and at a depth $d$ are given by the following equations (see Fig. 1 for the relevant geometry) [3].

$$
\begin{aligned}
d E_{r}\left(r, d, z^{\prime}\right)= & \frac{j \omega \mu_{0} I\left(z^{\prime}\right) d z^{\prime}}{4 \pi} \frac{\partial^{2} V\left(r, d, z^{\prime}\right)}{\partial r \partial z} \\
d E_{z}\left(r, d, z^{\prime}\right)= & \frac{j \omega \mu_{0} I\left(z^{\prime}\right) d z^{\prime}}{4 \pi} \\
& \times\left\{\left(\frac{\partial^{2}}{\partial z^{2}}+k_{g}^{2}\right) V\left(r, d, z^{\prime}\right)\right\}
\end{aligned}
$$

in which

$$
V\left(r, d, z^{\prime}\right)=\int_{0}^{\infty} \frac{\exp \left(\gamma_{g} d-\gamma_{0} z^{\prime}\right) J_{0}(\lambda r) \lambda d \lambda}{k_{g}^{2} \gamma_{0}+k_{0}^{2} \gamma_{g}}
$$

where $k_{0}$ and $k_{g}$ are propagation constants in the air and in the ground, given respectively by

$$
\begin{aligned}
& k_{0}^{2}=\omega^{2} \mu_{0} \varepsilon_{0}, \quad k_{g}^{2}=\omega^{2} \mu_{0} \varepsilon_{0} \varepsilon_{r g}+j \omega \mu_{0} \sigma_{g} \\
& \gamma_{0}^{2}=\lambda^{2}-k_{0}^{2}, \quad \gamma_{g}^{2}=\lambda^{2}-k_{g}^{2} .
\end{aligned}
$$

Equation (3) is the so-called Sommerfeld integral which requires time-consuming algorithms (e.g., [5], [6]) for its numerical evaluation.

To obtain the incident electric field in the time domain, the integration of (1) and (2) along the lightning channel followed by an inverse Fourier transformation is also required. Therefore, the direct use of (1) and (2) can be very costly in terms of computation time, particularly in view of the fact that for coupling calculations, the fields are to be determined not at a single point but along the whole buried cable.

Simplified expressions for the determination of the electric fields below the ground surface produced by a vertical lightning channel, as a function of the electric field at the air-soil interface, has been recently proposed in [4] by Cooray. The expressions proposed by Cooray for the vertical and horizontal components of the electric field in the frequency domain are given by

$$
\begin{aligned}
& E_{z}(j \omega, r, d)=E_{z}(j \omega, r, 0) \frac{\varepsilon_{0} \exp \left(-k_{g} d\right)}{\sigma_{g}+j \omega \varepsilon_{0} \varepsilon_{r g}} \\
& E_{r}(j \omega, r, d)=E_{r}(j \omega, r, 0) \exp \left(-k_{g} d\right) .
\end{aligned}
$$

In time domain, (6) and (7) read, respectively,

$$
\begin{aligned}
& E_{z}(t, r, d)=\int_{0}^{t} E_{z}(t-\tau, r, 0) \Psi(\tau) d \tau \\
& E_{r}(t, r, d)=\int_{0}^{t} E_{r}(t-\tau, r, 0) Y(\tau) d \tau
\end{aligned}
$$

where $\Psi(t)$ and $\mathrm{Y}(t)$ are the inverse Fourier transforms of $\left(\varepsilon_{0} \exp \left(-k_{g} d\right)\right) /\left(\sigma_{g}+j \omega \varepsilon_{0} \varepsilon_{r g}\right)$ and $\exp \left(-k_{g} d\right)$, respectively, and they are given by ${ }^{1}[4]$

$$
\begin{aligned}
& \Psi(t)=\int_{0}^{t} \Psi_{1}(t-\tau) Y(\tau) d \tau \\
& \Psi_{1}(t)=\frac{1}{\varepsilon_{r g}} \exp (-a t) \\
& Y(t)=\frac{\exp (-a t / 2) a t_{z}}{2 \sqrt{t^{2}-t_{z}^{2}}} I_{1}\left(\frac{a \sqrt{t^{2}-t_{z}^{2}}}{2}\right) u\left(t-t_{z}\right) \\
& \quad+\exp \left(-a t_{z} / 2\right) \delta\left(t-t_{z}\right)
\end{aligned}
$$

in which

$$
a=\frac{\sigma_{g}}{\varepsilon_{0} \varepsilon_{r g}} \quad \text { and } \quad t_{z}=d \sqrt{\mu_{0} \varepsilon_{0} \varepsilon_{r g}} .
$$

At the air-soil interface, when $d=0,(12)$ reduces to $\left.Y(t)\right|_{d=0}=\delta(t)$, assuring the continuity of the horizontal electric field at the air-soil interface.

In (8) and (9), the vertical and horizontal electric field components at ground surface $E_{z}(t, r, 0)$ and $E_{r}(t, r, 0)$ can be calculated with reasonable accuracy assuming a perfectly conducting ground for the vertical electric field component [7], and the Cooray-Rubinstein approximation for the horizontal component [8], [9].

Fig. 2 presents a comparison between the horizontal electric field calculated using Cooray's simplified expressions and the nearly exact numerical solutions of (1) published by Zeddam in [10]. The results are for an observation point located $100 \mathrm{~m}$ from the stroke location at two different depths, namely $1 \mathrm{~m}$ and $10 \mathrm{~m}$, for two values for ground conductivity $(0.01 \mathrm{~S} / \mathrm{m}$ and $0.001 \mathrm{~S} / \mathrm{m}$ ). As seen in Fig. 2, the simplified approach proposed by Cooray yields satisfactory results.

\section{COUPLing OF AN EXTERnAl Electromagnetic Field to A BURIED CABLE}

Consider a horizontal buried cable of length $L$ (cylindrical conductor with an insulated jacket) located along the $x$-axis at depth $d$. Assuming that the vertical component of electric field can be neglected below the ground surface [8], voltages and currents along the cable induced by a nearby lightning can be calculated using the field-to-transmission line equations expressed in the frequency domain [2], [10], [11],

$$
\frac{d V(x)}{d x}+Z^{\prime} I(x)=E_{x}^{e}(x, z=-d)
$$

\footnotetext{
${ }^{1}$ Note that (11) and (12), slightly different from the original equations (20) and (21) in [4], are the correct expressions for $\Psi_{1}(t)$ and $Y(t)$.
} 

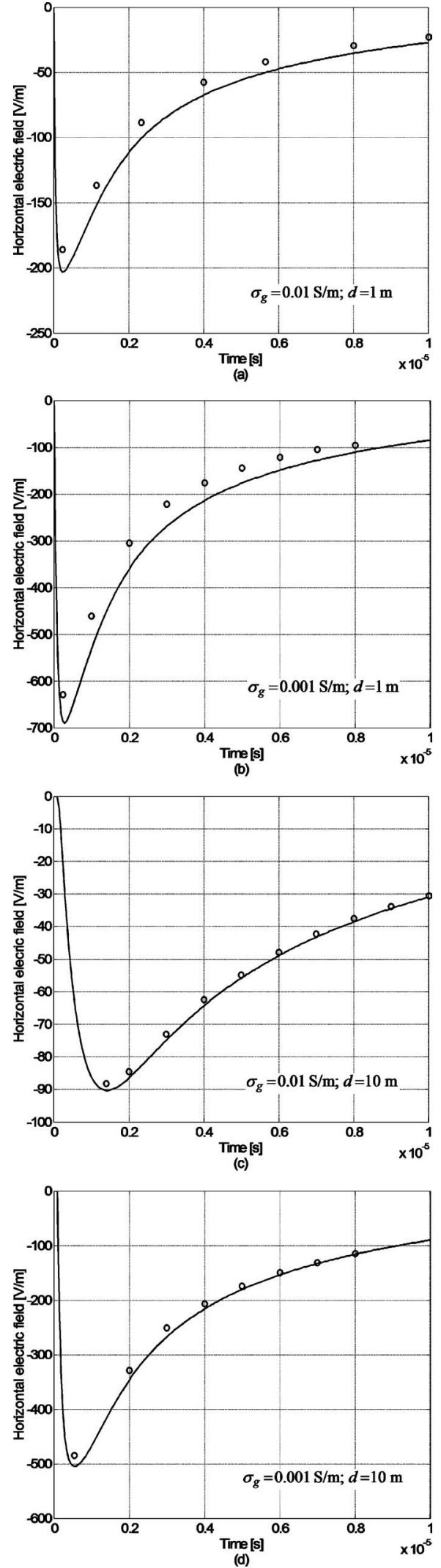

Fig. 2. Comparison between the horizontal electric field calculated at two different depths $(1 \mathrm{~m}$ and $10 \mathrm{~m})$ and for two different ground conductivities $(0.01 \mathrm{~S} / \mathrm{m}$ and $0.001 \mathrm{~S} / \mathrm{m})$ using the Cooray formula (9) (solid line) and the nearly exact numerical solutions of (1) (circles), taken from [10]. Observation point is $100 \mathrm{~m}$ from the stroke location. Lighting return stroke current peak is $15 \mathrm{kA}$.

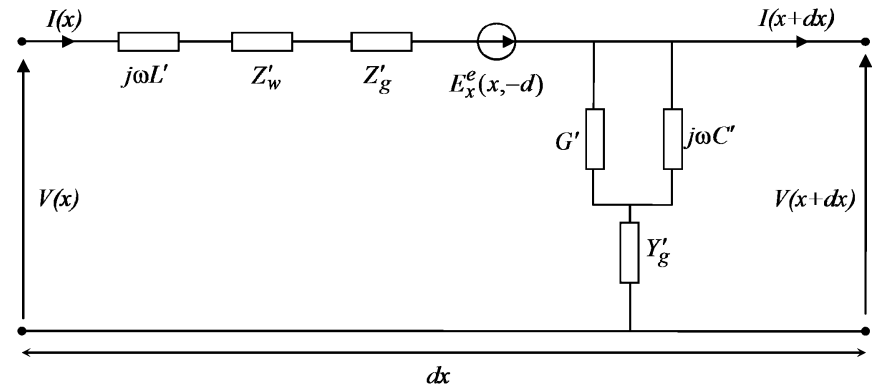

Fig. 3. Differential equivalent coupling circuit for a buried cable illuminated by an external field.

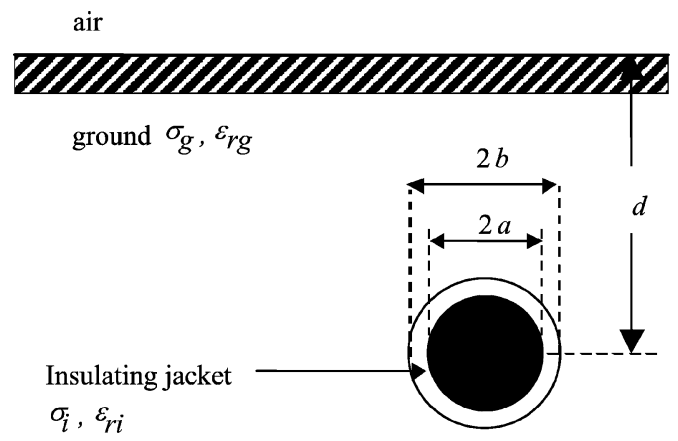

Fig. 4. Geometry of the buried cable (cylindrical conductor of radius $a$ with an insulating jacket).

$$
\frac{d I(x)}{d x}+Y^{\prime} V(x)=0
$$

where the longitudinal impedance is

$$
Z^{\prime}=j \omega L^{\prime}+Z_{w}^{\prime}+Z_{g}^{\prime}
$$

and the transversal admittance is:

$$
Y^{\prime}=\frac{\left(G^{\prime}+j \omega C^{\prime}\right) \cdot Y_{g}^{\prime}}{\left(G^{\prime}+j \omega C^{\prime}\right)+Y_{g}^{\prime}}
$$

in which (see Figs. 3 and 4)

- $L^{\prime}$ and $C^{\prime}$ are respectively the per-unit-length longitudinal inductance and transverse capacitance of the cable

$$
\begin{aligned}
L^{\prime} & =\frac{\mu_{o}}{2 \pi} \ln \left(\frac{b}{a}\right) \\
C^{\prime} & =\frac{2 \pi \varepsilon_{0} \varepsilon_{r i}}{\ln (b / a)}
\end{aligned}
$$

- $G^{\prime}$ is the per-unit-length transverse conductance of the cable

$$
G^{\prime}=\frac{\sigma_{i}}{\varepsilon_{0} \varepsilon_{r i}} C^{\prime}
$$

$-Z_{w}^{\prime}$ is the per-unit-length internal impedance of the conductor (wire). Assuming an axial symmetry for the current, the following expression can be adopted [12]:

$$
Z_{w}^{\prime}=\frac{\gamma_{w} I_{0}\left(\gamma_{w} a\right)}{2 \pi a \sigma_{w} I_{1}\left(\gamma_{w} a\right)}
$$


where $\gamma_{w}=\sqrt{j \omega \mu_{0}\left(\sigma_{w}+j \omega \varepsilon_{0} \varepsilon_{r w}\right)}$ is the propagation constant in the wire and the $\varepsilon_{r w}$ relative permittivity of the wire.

- $Z_{g}^{\prime}$ and $Y_{g}^{\prime}$ are the per-unit-length ground impedance and ground admittance, respectively. These two quantities are related through the following expression [13]:

$$
Y_{g}^{\prime} \cong \frac{\gamma_{g}^{2}}{Z_{g}^{\prime}}
$$

where $\gamma_{g}$ is the propagation constant in the ground, which can be expressed as $\gamma_{g}=\sqrt{j \omega \mu_{0}\left(\sigma_{g}+j \omega \varepsilon_{0} \varepsilon_{r g}\right)}$, and equations for $Z_{g}^{\prime}$ are discussed in Section IV.

\section{GROUND IMPEDANCE EXPRESSIONS}

\section{A. Pollaczek and Sunde's Expressions}

The best known model for the ground impedance was proposed by Pollaczek [14] in 1926

$$
Z_{g}^{\prime}=\frac{j \omega \mu_{0}}{2 \pi}\left[K_{0}\left(\frac{b}{p}\right)-K_{0}\left(\frac{2 d}{p}\right)+J\right]
$$

where

$$
J=\int_{-\infty}^{+\infty} \frac{\exp \left[-2 d \sqrt{\beta^{2}+\frac{1}{p^{2}}}\right]}{|\beta|+\sqrt{\beta^{2}+\frac{1}{p^{2}}}} \exp (j \omega b) d \beta
$$

is the so-called Pollaczek Integral, in which $K_{0}$ is the modified Bessel function of second class and zero order, $p$ is the complex depth of the skin effect layer $p=1 / \sqrt{j \omega \mu_{0} \sigma_{g}}$, and $d$ is the depth of the cable.

Sunde [15] proposed an expression for the mutual inductance of two buried cables located at the same depth $d$ and separated by a distance $y$, which is given by

$$
\begin{aligned}
& j \omega L^{\prime}=\frac{j \omega \mu_{0}}{2 \pi}\left[K_{0}\left(\gamma_{g} y\right)\right.-K_{0}\left(\gamma_{g} \sqrt{y^{2}+4 d^{2}}\right) \\
&\left.+2 \int_{0}^{\infty} \frac{\exp (-2 d u) \cos u y}{\alpha+u} d u\right]
\end{aligned}
$$

where $\alpha=\sqrt{u^{2}+\gamma_{g}^{2}}$.

The ground impedance of a single buried cable can be obtained using (23), by replacing $y$ with $b$, the cable radius. This yields

$$
\begin{aligned}
Z_{g}^{\prime}=\frac{j \omega \mu_{0}}{2 \pi}\left[K_{0}\left(\gamma_{g} b\right)\right. & -K_{0}\left(\gamma_{g} \sqrt{b^{2}+4 d^{2}}\right) \\
& \left.+2 \int_{0}^{\infty} \frac{\exp (-2 d u) \cos u b}{\alpha+u} d u\right]
\end{aligned}
$$

Comparing (22) with (24), one can see that the Pollaczek's expression (22) corresponds to Sunde's expression (24), when the displacement current is neglected. Indeed, if $\gamma_{g}=\sqrt{j \omega \mu_{0}\left(\sigma_{g}+j \omega \varepsilon_{0} \varepsilon_{r g}\right)}$ is replaced by $\gamma_{g} \cong \sqrt{j \omega \mu_{0} \sigma_{g}}$, (24) reduces to (22).

\section{B. Other Expressions for the Ground Impedance Found in the} Literature

Vance formula [11]: Vance developed the following formula for the ground impedance considering the ground as a lossy cylindrical dielectric surrounding the cable

$$
Z_{g}^{\prime}=\frac{\omega \mu_{0}}{2 \pi b \gamma_{g}} \frac{H_{0}^{(1)}\left(j \gamma_{g} b\right)}{H_{1}^{(1)}\left(j \gamma_{g} b\right)}
$$

where $H_{0}^{(1)}$ and $H_{1}^{(1)}$ are Hankel functions.

Semlyen and Wedepohl formula. The following expression for the ground impedance was reported in [16]

$$
Z_{g}^{\prime}=\frac{j \omega \mu_{0}}{2 \pi} \ln \left(b+\frac{1}{m b}\right)
$$

where $m=\sqrt{j \omega \mu_{0} \sigma_{g}}$ is the propagation constant of the ground, neglecting the displacement current.

Saad-Gaba-Giroux formula. Approximating the Pollaczek integral, Saad, Gaba and Giroux [17] obtained the following expression:

$$
Z_{g}^{\prime}=\frac{\rho m^{2}}{2 \pi}\left(K_{0}(m b)+\frac{2}{4+m^{2} b^{2}} \cdot \exp (-2 d u)\right)
$$

where $m$ is the same as in (26), $K_{0}$ is the same as in (22) and $\rho$ is the ground resistivity.

Bridges formula: Starting from the rigorous scattering solution for a buried cable, Bridges [18] derived a frequency domain integral equation for cable current and a general expression for the ground impedance. Using the transmission line approximation and neglecting the displacement current, Bridges [18] derived the following approximate formula for the ground impedance:

$$
Z_{g}^{\prime}=-\frac{j \omega \mu_{0}}{2 \pi} \ln \left(\gamma_{g} \frac{\Gamma}{2} b\right)
$$

where $\Gamma=1.7811 \ldots$ and $\gamma_{g} \cong \sqrt{j \omega \mu_{0} \sigma_{g}}$.

\section{Proposed Logarithmic Approximation}

The Sunde's general formula (24) being expressed in terms of Bessel functions and infinite integrals, we propose the following logarithmic approximation for the ground impedance:

$$
Z_{g}^{\prime}=\frac{j \omega \mu_{0}}{2 \pi} \ln \left(\frac{1+\gamma_{g} b}{\gamma_{g} b}\right)
$$

This expression is proposed by analogy with overhead lines, where it has been shown [7] that the Sunde's logarithmic approximation is in excellent agreement with the general expression for the ground impedance.

Fig. 5 presents a comparison between the various proposed approximations for a cable of $2.4 \mathrm{~cm}$ diameter, buried $1 \mathrm{~m}$ below the ground surface. Two different values for ground conductivity have been considered, namely, $\sigma_{g}=0.01 \mathrm{~S} / \mathrm{m}$ and $\sigma_{g}=0.001$ $\mathrm{S} / \mathrm{m}$. The ground relative permittivity is assumed to be $\varepsilon_{r g}=10$.

It can be seen that for the considered frequency range, $1 \mathrm{kHz}-30 \mathrm{MHz}$, all the considered expressions for the ground impedance provide similar results. Therefore, for the analysis 


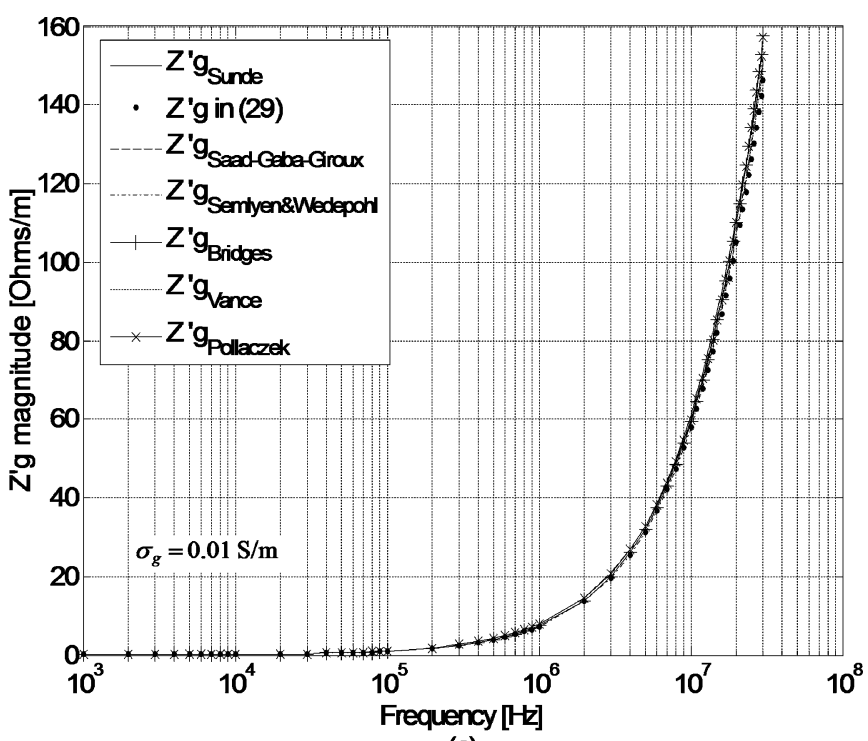

(a)

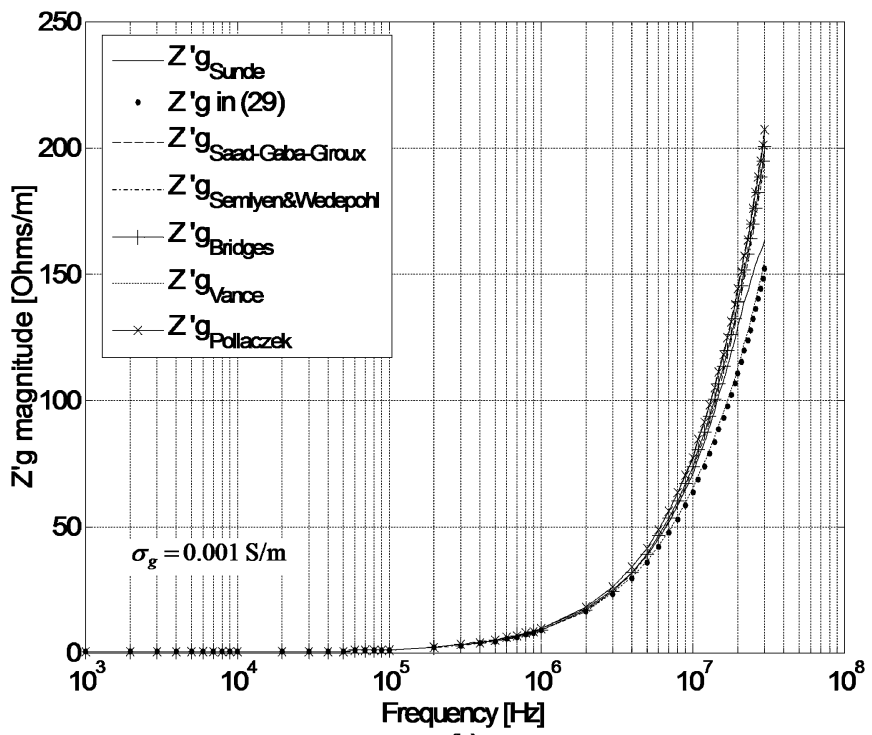

(b)

Fig. 5. Comparison between different closed form approximations for ground impedances and Sunde's general formula (24), for a buried cable having an external radius $b=1.2 \mathrm{~cm}$ placed at a depth $d=1 \mathrm{~m}$. (a) $\sigma_{g}=0.01 \mathrm{~S} / \mathrm{m}$, $\varepsilon_{r g}=10$. (b) $\sigma_{g}=0.001 \mathrm{~S} / \mathrm{m}, \varepsilon_{r g}=10$.

of lightning induced disturbances, which are characterized by significant frequency components not exceeding $10 \mathrm{MHz}$ or so, any of the above approximate formulas can be employed. However, the use of the logarithmic formula (29) is suggested for the following reasons:

- It is in excellent agreement with the general Sunde's expression.

- Its implementation is very simple and does not require any numerical treatment.

- Finally, unlike most of the considered approximations, it has an asymptotic behaviour at high frequencies. Hence, the corresponding transient ground resistance in time domain has no singularity at $t=0$ [7], [19]. Indeed, it is easy to show (see similar developments for overhead lines in
[7] and [19]) that

$$
\lim _{\omega \rightarrow \infty} Z_{g}^{\prime}=\frac{1}{2 \pi b} \sqrt{\frac{\mu_{0}}{\varepsilon_{0} \varepsilon_{r g}}}
$$

and, therefore, the early-time response of the transient ground resistance, defined as $\xi_{g}^{\prime}=\mathrm{F}^{-1}\left\{Z_{g}^{\prime} / j \omega\right\}$, is given by the initial value theorem

$$
\xi_{g}^{\prime}(t=0)=\lim _{\omega \rightarrow \infty} j \omega \frac{Z_{g}^{\prime}}{j \omega}=\frac{1}{2 \pi b} \sqrt{\frac{\mu_{0}}{\varepsilon_{0} \varepsilon_{r g}}} .
$$

\section{RELATIVE IMPORTANCE OF LINE PARAMETERS}

\section{A. Longitudinal Parameters}

Fig. 6 presents a comparison among longitudinal parameters of a buried cable, namely the ground impedance, the wire impedance, and the inductive impedance $\omega L^{\prime}$.

The results are obtained for a cable having the following geometrical parameters: $a=1 \mathrm{~cm}, b=1.2 \mathrm{~cm}$, relative permittivity of the insulating jacket $\varepsilon_{r i}=3$, cable depth $d=1 \mathrm{~m}$.

Two different values for ground conductivity were considered, namely $0.01 \mathrm{~S} / \mathrm{m}$ in Fig. 6(a) and $0.001 \mathrm{~S} / \mathrm{m}$ in Fig. 6(b). The ground permittivity is fixed at $\varepsilon_{r g}=10$. The results show that, within the frequency range $1 \mathrm{kHz}-30 \mathrm{MHz}$, the major contribution to the longitudinal impedance comes from the ground impedance. Further, the wire impedance is much smaller than the ground impedance and hence can be neglected.

\section{B. Transverse Parameters}

If one neglects the transverse conductance, the transverse admittance per-unit-length becomes

$$
Y^{\prime}=\frac{j \omega C^{\prime} \cdot Y_{g}^{\prime}}{j \omega C^{\prime}+Y_{g}^{\prime}}
$$

The expression for the transverse admittance can be written in a more convenient form as follows:

$$
Y^{\prime}=j \omega C^{\prime}+Y_{\text {add }}^{\prime}, \quad \text { where } Y_{\text {add }}^{\prime}=-\frac{\left(j \omega C^{\prime}\right)^{2}}{j \omega C^{\prime}+Y_{g}^{\prime}} .
$$

Fig. 7 presents a comparison between $1 /\left|Y_{g}^{\prime}\right|$ and $1 / \omega C^{\prime}$ as a function of frequency, for two values of ground conductivity. It can be seen that at low frequencies, the major contribution to the transverse admittance comes from the capacitance. On the contrary, at higher frequencies the ground admittance contribution becomes more significant. For a ground conductivity of $0.001 \mathrm{~S} / \mathrm{m}$, for example, the effect of ground admittance becomes dominant at frequencies above $100 \mathrm{kHz}$. This is in contrast with typical overhead lines in which the effect of the ground admittance can be neglected for the frequency range of interest [20].

\section{TIME-Domain ANALYSIS OF FIELD-TO-BURIED CABLE COUPLING EQUATIONS}

A time domain representation of field-to-transmission line coupling equations is sometimes preferable because it allows 


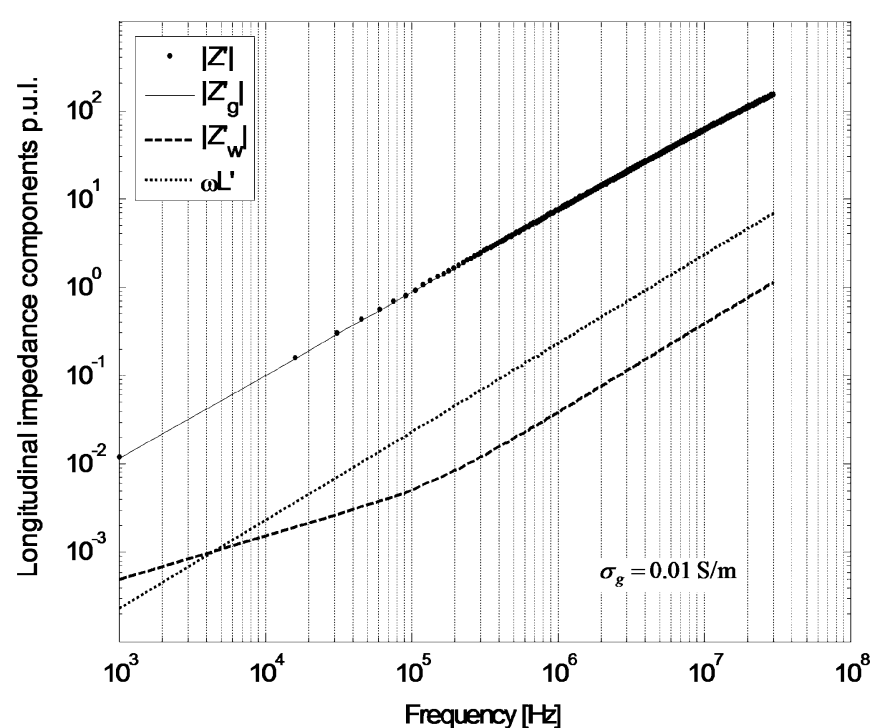

(a)

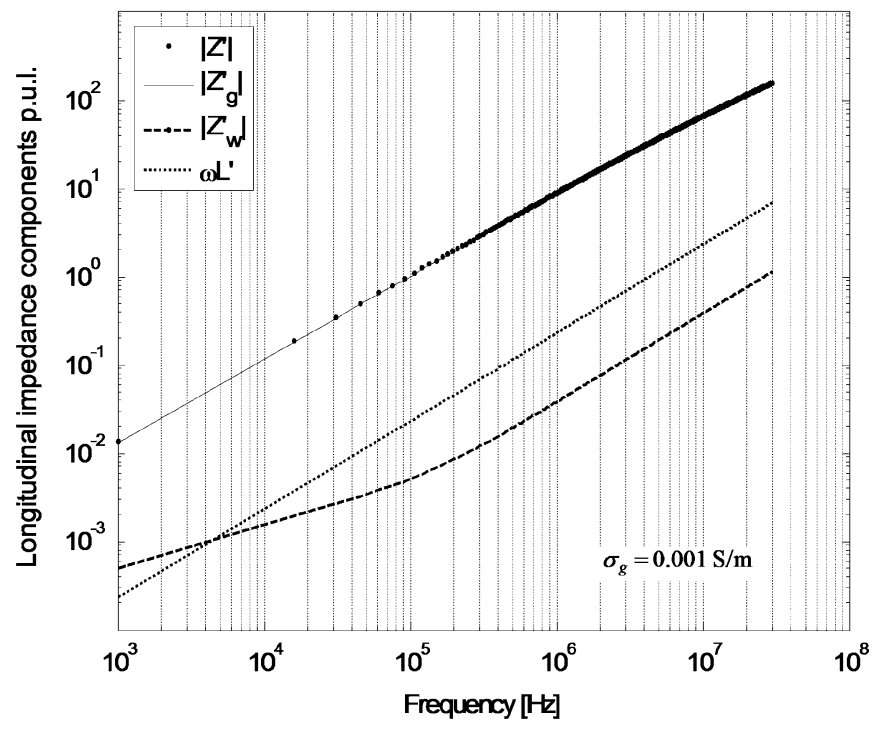

(b)

Fig. 6. Comparison of the magnitudes of the components of the longitudinal impedance of a buried cable having the following parameters: $a=1 \mathrm{~cm}, b=$ $1.2 \mathrm{~cm}, \varepsilon_{r i}=3, \varepsilon_{r g}=10$. (a) $\sigma_{g}=0.01 \mathrm{~S} / \mathrm{m}$. (b) $\sigma_{g}=0.001 \mathrm{~S} / \mathrm{m}$.

handling in a straightforward manner nonlinear phenomena such as the presence of nonlinear protective devices at the line terminals [20]. On the other hand, frequency dependent parameters, such as the ground impedance and ground admittance, need to be represented using convolution integrals, which require time consuming algorithms.

The field-to-transmission line coupling equations (13) and (14) can be converted into the time domain to obtain the following expressions:

$$
\begin{aligned}
& \frac{\partial v(x, t)}{\partial x}+L^{\prime} \frac{\partial i(x, t)}{\partial t}+\xi_{g}^{\prime}(t) \otimes \frac{\partial i(x, t)}{\partial t}=E_{x}^{e}(x,-d, t) \\
& \frac{\partial i(x, t)}{\partial x}+C^{\prime} \frac{\partial v(x, t)}{\partial t}+\eta_{g}^{\prime}(t) \otimes \frac{\partial i(x, t)}{\partial t}=0
\end{aligned}
$$

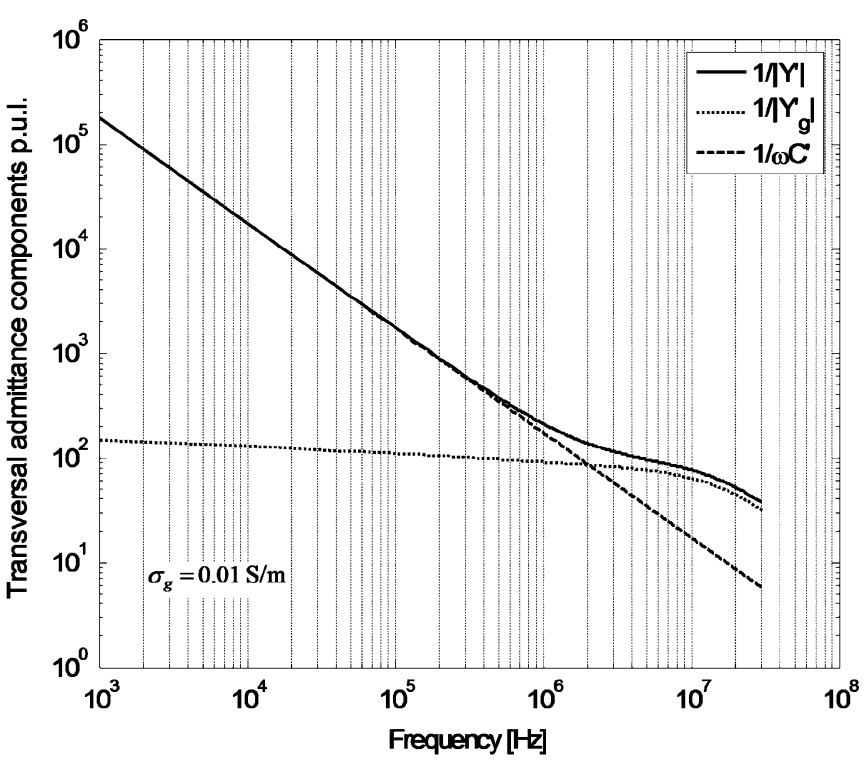

(a)

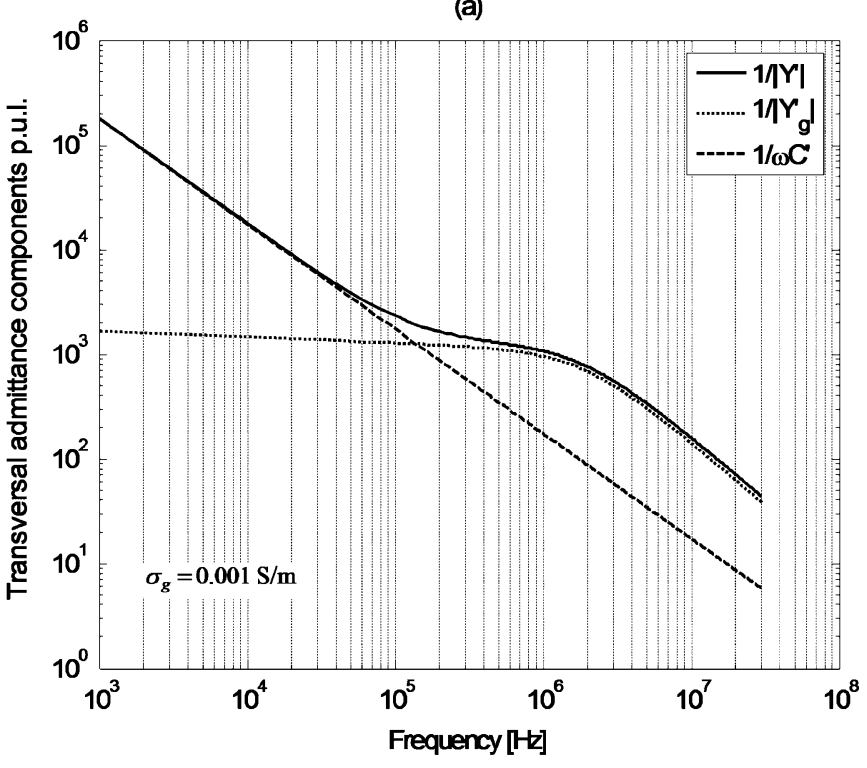

(b)

Fig. 7. Comparison between the components of the transverse admittance of a buried cable having the following parameters: $a=1 \mathrm{~cm}, b=1.2 \mathrm{~cm}$, $\varepsilon_{r i}=3, \varepsilon_{r g}=10$. (a) $\sigma_{g}=0.01 \mathrm{~S} / \mathrm{m}$. (b) $\sigma_{g}=0.001 \mathrm{~S} / \mathrm{m}$.

where:

$\xi_{g}^{\prime}(t)$ transient ground resistance defined as the inverse Fourier transform of $\left(Z_{g}^{\prime} / j \omega\right)$;

$\otimes \quad$ convolution product;

$\eta_{g}^{\prime}(t)$ transient ground conductance defined as the inverse Fourier transform of $\left(Y_{\text {add }}^{\prime}\right) /(j \omega)$, where $Y_{\text {add }}^{\prime}$ is defined by (33).

\section{A. Transient Ground Resistance and Conductance in the Time Domain}

The general expression for the ground impedance in the frequency domain (24) does not have an analytical inverse Fourier transform. Thus, elements of the transient ground resistance 


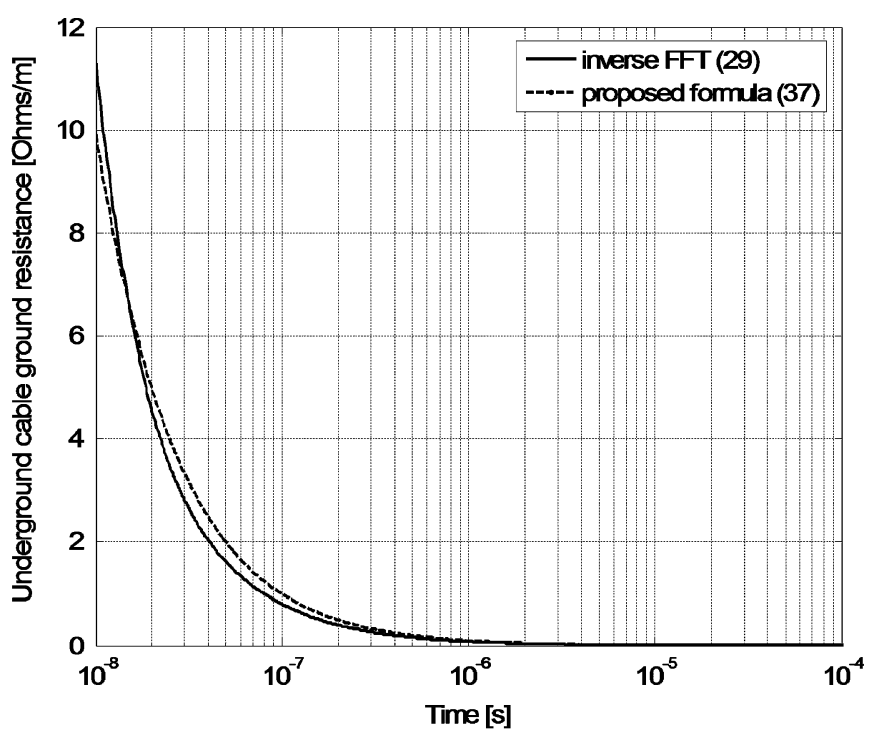

Fig. 8. Transient ground resistance of a conductor located $1 \mathrm{~m}$ below the earth surface. Ground electrical parameters: $\sigma_{g}=0.01 \mathrm{~S} / \mathrm{m}, \varepsilon_{r g}=10$. Comparison between the inverse Fourier transform of (29) $\left(F^{-1}\left\{Z_{g}^{\prime} / j \omega\right\}\right)$ and the proposed expression (37).

in the time domain are, in general, to be determined using a numerical inverse Fourier transform algorithm.

For the case of an overhead wire located at a height $h$ above ground, however, the following analytical expressions are shown to be reasonable approximations to the numerical values obtained using an inverse FFT [19].

$$
\begin{aligned}
\xi_{g}^{\text {overhead }}(t) \cong \min & \left\{\frac{1}{2 \pi h} \sqrt{\frac{\mu_{0}}{\varepsilon_{0} \varepsilon_{r g}}}, \frac{\mu_{0}}{\pi \tau_{g}}\left[\frac{1}{2 \sqrt{\pi}} \sqrt{\frac{\tau_{g}}{t}}\right.\right. \\
+ & \left.\left.\frac{1}{4} \exp \left(\frac{\tau_{g}}{t}\right) \operatorname{erfc}\left(\sqrt{\frac{\tau_{g}}{t}}\right)-\frac{1}{4}\right]\right\}
\end{aligned}
$$

where $\tau_{g}=h^{2} \mu_{0} \sigma_{g}$, and erfc is the complementary error function.

Again, by analogy with overhead lines, we can replace $h$ in (36) by $b$ and adapt the above analytical approximation to the case of an underground cable

$$
\begin{aligned}
\xi_{g}^{\prime}(t) \cong \min \left\{\frac{1}{2 \pi b}\right. & \sqrt{\frac{\mu_{0}}{\varepsilon_{0} \varepsilon_{r g}}}, \frac{\mu_{0}}{\pi \tau_{g}}\left[\frac{1}{2 \sqrt{\pi}} \sqrt{\frac{\tau_{g}}{t}}\right. \\
& \left.\left.+\frac{1}{4} \exp \left(\frac{\tau_{g}}{t}\right) \operatorname{erfc}\left(\sqrt{\frac{\tau_{g}}{t}}\right)-\frac{1}{4}\right]\right\}
\end{aligned}
$$

where $\tau_{g}=b^{2} \mu_{0} \sigma_{g}$.

Fig. 8 presents a comparison between the numerical inverse Fourier transform of (29) $\left(F^{-1}\left\{Z_{g}^{\prime} / j \omega\right\}\right)$ and the proposed expression (37). It can be seen that (37) is in excellent agreement with the numerical inverse Fourier transform of (29).

The time-domain ground transient conductance is defined as

$$
\eta_{g}^{\prime}(t)=F^{-1}\left\{\frac{Y_{\mathrm{add}}^{\prime}}{j \omega}\right\} \text {. }
$$

To the best of our knowledge, analytical expressions for the inverse Fourier transform are not available for the ground transient conductance. Thus, the ground transient conductance has

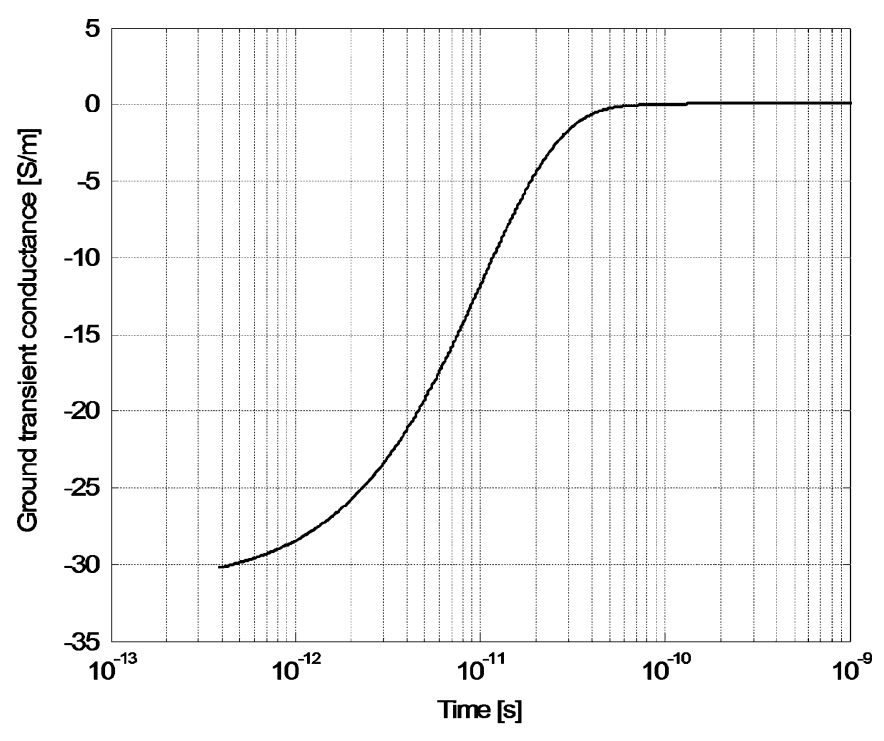

Fig. 9. The inverse Fourier transform of $Y_{\text {add }}^{\prime} / j \omega$ in the early-time region.

to be determined using a numerical inverse Fourier transform. It is worth noting that using the logarithmic approximation (29) for the computation of ground admittance, the ground transient conductance tends to an asymptotic value when $t$ tends to zero. Indeed, using the same approach as for the transient ground resistance, an asymptotical value of the $Y_{\text {add }}^{\prime}$ can be calculated in frequency domain:

$$
\lim _{\omega \rightarrow \infty} Y_{\text {add }}^{\prime}=-\frac{2 \pi\left(\varepsilon_{0} \varepsilon_{r i}\right)^{2} \mu_{0}}{b\left(\varepsilon_{0} \varepsilon_{r g} \mu_{0}\right)^{3 / 2}\left(\ln \frac{b}{a}\right)^{2}}
$$

and applying the initial value theorem, we get

$$
\eta_{g}^{\prime}(t=0)=\lim _{\omega \rightarrow \infty} j \omega \frac{Y_{\text {add }}^{\prime}}{j \omega}=-\frac{2 \pi\left(\varepsilon_{0} \varepsilon_{r i}\right)^{2} \mu_{0}}{b\left(\varepsilon_{0} \varepsilon_{r g} \mu_{0}\right)^{3 / 2}\left(\ln \frac{b}{a}\right)^{2}} .
$$

Fig. 9 presents $\eta_{g}^{\prime}(t)$ in the early-time region obtained by inverse Fourier transformation of $Y_{\text {add }}^{\prime} / j \omega$, for an underground cable with the following characteristics: $b=1.2 \mathrm{~cm}, a=1 \mathrm{~cm}$, and $\varepsilon_{r i}=5$. It can be seen that the transient ground conductance at $t=0$ tends to an initial value of about $-30 \mathrm{~S} / \mathrm{m}$, which corresponds to the value predicted by (40) for the considered parameters.

The finite-difference time-domain (FDTD) solutions of the coupling equations are presented in the Appendix.

\section{FREQUENCY-DOMAIN SOLUTIONS}

One method to solve the field-to-transmission line equations (13) and (14) in the frequency domain is to use the expressions for the line voltage and current for a point voltage source and current source, respectively, that is, the Green's functions. For an arbitrary incident field exciting the cable (vertical electric field component underground is neglected), the solutions for the cable current and voltage at an arbitrary position $x$ on the cable can be written as the following integrals of the Green's 
functions [13]:

$$
\begin{gathered}
I(x)=\int_{0}^{L} G_{I}\left(x, x_{s}\right) V_{s}^{\prime} d x_{s} \\
V(x)=\int_{0}^{L} G_{V}\left(x, x_{s}\right) V_{s}^{\prime} d x_{s}
\end{gathered}
$$

where $G_{I}$ and $G_{V}$ represent the Green's functions for the cable current and voltage, respectively, which are given by [13]

$$
\begin{aligned}
& G_{I}\left(x, x_{s}\right) \\
& = \begin{cases}\frac{e^{-\gamma L}}{2 Z_{c}\left(1-\rho_{1} \rho_{2} e^{-2 \gamma L}\right)}\left[e^{-\gamma\left(x_{s}-L\right)}-\rho_{2} e^{\gamma\left(x_{s}-L\right)}\right] \\
\cdot\left(e^{\gamma x}-\rho_{1} e^{-\gamma x}\right), \quad \text { for } x<x_{s} \\
\frac{e^{-\gamma L}}{2 Z_{c}\left(1-\rho_{1} \rho_{2} e^{2 \gamma L}\right)}\left[e^{-\gamma(x-L)}-\rho_{2} e^{\gamma(x-L)}\right] \\
\cdot\left(e^{\gamma x_{s}}-\rho_{1} e^{-\gamma x_{s}}\right), & \text { for } x<x_{s}\end{cases} \\
& G_{V}\left(x, x_{s}\right) \\
& = \begin{cases}\frac{-e^{-\gamma L}}{2\left(1-\rho_{1} \rho_{2} e^{-2 \gamma L}\right)}\left[e^{-\gamma\left(x_{s}-L\right)}-\rho_{2} e^{\gamma\left(x_{s}-L\right)}\right] \\
\cdot\left(e^{\gamma x}+\rho_{1} e^{-\gamma x}\right), & \text { for } x<x_{s} \\
\frac{e^{-\gamma L}}{2\left(1-\rho_{1} \rho_{2} e^{-2 \gamma L}\right)}\left[e^{-\gamma(x-L)}+\rho_{2} e^{\gamma(x-L)}\right] \\
\cdot\left(e^{\gamma x_{s}}-\rho_{1} e^{-\gamma x_{s}}\right), & \text { for } x<x_{s}\end{cases}
\end{aligned}
$$

where $\gamma=\sqrt{Z^{\prime} Y^{\prime}}$ is the line complex propagation constant along the cable and $Z_{c}=\sqrt{Z^{\prime} / Y^{\prime}}$ is the cable characteristic impedance.

A frequency domain solution is particularly useful when one is interested in calculating the inner response of a shielded cable, which involves the cable transfer function, a highly frequency dependent quantity.

\section{SUMMARY AND CONCLUSIONS}

A review of theoretical methods to compute lightning induced currents and voltages on buried cables has been presented. The evaluation of such induced disturbances requires the calculation of the electric field produced by lightning along the cable path.

In Section II of the paper, we have shown that the Cooray's simplified formula is capable of predicting accurately the horizontal electric field penetrating the ground, at distances as close as $100 \mathrm{~m}$.

Regarding the parameters of the buried cables, a comparison of several approximations of the ground impedance has been presented and discussed. We have shown that Pollaczek's expression corresponds to Sunde's general expression, when the displacement current is neglected. The analysis has also shown that all the proposed approximations provide very similar results for the considered range of frequencies $(1 \mathrm{kHz}-30 \mathrm{MHz})$. Most of the approximate formulas neglect the contribution of the displacement current, and therefore predict values for the ground impedance which tend to infinity at higher frequencies. This corresponds in the time domain to a singularity of the ground transient resistance at $t=0$. By analogy to the Sunde's approximation for the ground impedance of overhead lines, we have proposed a logarithmic approximation for the ground impedance of a buried cable. In addition, unlike most of the considered approximations, it has an asymptotic behavior at high frequencies;
TABLE I

SUMMARY OF THE RECOMMENDED METHODS FOR THE CALCULATION OF LIGHTNING INDUCED VOLTAGES ON A BURIED CABLE

\begin{tabular}{lc}
\hline \hline QUANTITY & RECOMMENDED METHOD, EQUATION, OR VALUE \\
\hline \hline Horizontal electric field along the cable, $E_{r}$ & Cooray's formula (9) \\
Wire impedance, $Z_{w}^{\prime}$ & $\approx 0$ \\
Ground impedance (frequency-domain), $Z_{g}^{\prime}$ & Logarithmic approximation (29) \\
Ground admittance (frequency-domain), $Y_{g}^{\prime}$ & Equation (21) \\
Transient ground resistance (time-domain), $\xi_{g}^{\prime}$ & Equation (37) \\
Transient ground admittance (time-domain), $\eta_{g}^{\prime}$ & Numerical evaluation using (33) and (38) \\
\hline \hline
\end{tabular}

therefore, the corresponding transient ground resistance in the time domain has no singularity at $t=0$.

It is also demonstrated that within the frequency range of interest, the wire impedance can be neglected due to its small contribution to the overall longitudinal impedance of the line. The ground admittance, however, can play an important role at high frequencies ( $1 \mathrm{MHz}$ or so), especially in the case of poor ground conductivity. The ground admittance needs to be taken into account in calculations of lightning induced currents and voltages on buried cables. This is in contrast with the case of overhead lines in which its contribution is generally negligible even in the megahertz range.

We have also investigated the time-domain representation of field-to-transmission line coupling equations. The coupling model includes the effect of ground admittance which appears in terms of an additional convolution integral. An analytical expression for the ground transient resistance in the time domain has also been proposed which is shown to be sufficiently accurate and nonsingular.

Finally, we presented a time-domain solution of field-toburied cable coupling equations using the point centered FDTD method, and a frequency-domain solution using Green's functions. In our companion paper (Part II), we will compare both solutions to experimental waveforms obtained using triggered lightning.

Table I presents a summary of the approximate methods discussed in the paper that we recommend for the determination of the electric field and transmission line parameters in calculating lightning induced currents and voltages on buried cables.

\section{APPENDIX}

\section{FDTD SOLUTIONS OF THE COUPLING EQUATIONS}

The coupling equations written in the time domain, taking into account the transient ground resistance and conductance, are reproduced here for convenience:

$$
\begin{aligned}
\frac{\partial v(x, t)}{\partial x}+ & R^{\prime} i(x, t)+L^{\prime} \frac{\partial i(x, t)}{\partial t} \\
& +\int_{0}^{t} \xi_{g}^{\prime}(t-\tau) \frac{\partial i(x, \tau)}{\partial \tau} d \tau=E_{x}^{s}(x,-d, t)
\end{aligned}
$$




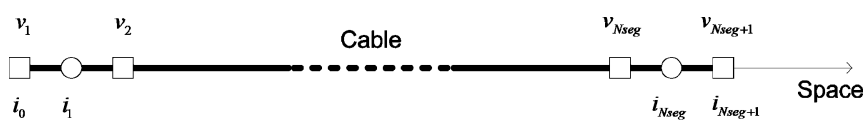

(a)

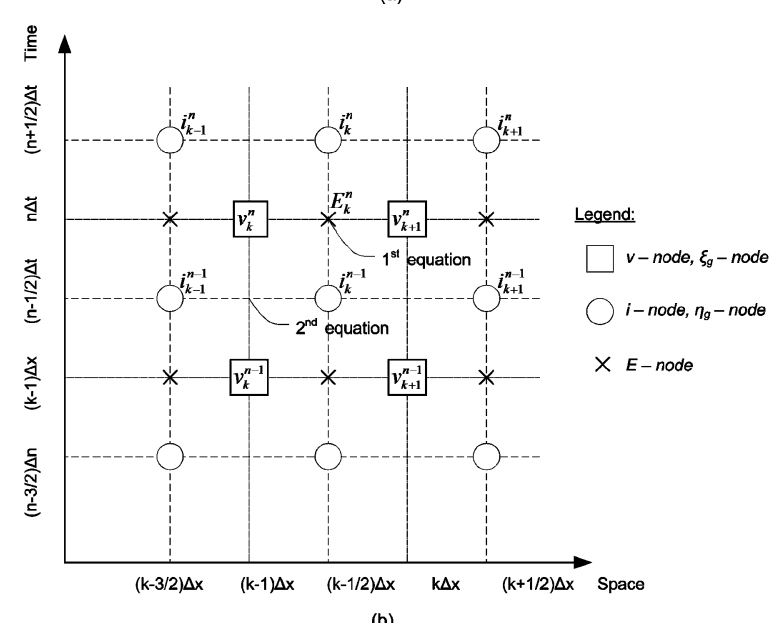

(b)

Fig. 10. FDTD 1st order integration scheme. (a) Schematic representation of the spatial discretization along the cable. (b) Time and spatial discretization.

$$
\begin{aligned}
\frac{\partial i(x, t)}{\partial x}+G^{\prime} v(x, t)+ & C^{\prime} \frac{\partial v(x, t)}{\partial t} \\
& +\int_{0}^{t} \eta_{g}^{\prime}(t-\tau) \frac{\partial v(x, \tau)}{\partial \tau} d \tau=0 .
\end{aligned}
$$

To solve the transmission line coupling equations in the time domain, we use the finite difference time domain (FDTD) technique (e.g., [21]). In the following, the FDTD 1st order point centered integration scheme (see Fig. 10), applied to the case of a buried cable, is presented.

The point-centered FDTD representation of (A1) for the node $((k-1 / 2) \Delta x, n \Delta t)$ is given by

$$
\begin{aligned}
\frac{\partial}{\partial x} v & ((k-1 / 2) \Delta x, n \Delta t)+R^{\prime} i((k-1 / 2) \Delta x, n \Delta t) \\
& +L^{\prime} \frac{\partial i((k-1 / 2) \Delta x, n \Delta t)}{\partial t} \\
& +\int_{0}^{n \Delta t} \xi_{g}^{\prime}(n \Delta t-\tau) \frac{i((k-1 / 2) \Delta x, n \Delta t)}{\partial t} d \tau \\
= & E_{x}^{s}((k-1 / 2) \Delta x,-d, n \Delta t) .
\end{aligned}
$$

Using the following notations,

$$
\begin{aligned}
v_{k}^{n} & =v((k-1) \Delta x, n \Delta t) \\
i_{k}^{n} & =i((k-1 / 2) \Delta x,(n+1 / 2) \Delta t) \\
\xi^{n} & =\xi_{g}^{\prime}(n \Delta t) \\
E_{k}^{n} & =E((k-1 / 2) \Delta x,-d, n \Delta t) .
\end{aligned}
$$

(A3) can be written more compactly in the following form:

$$
\frac{v_{k+1}^{n}-v_{k}^{n}}{\Delta x}+R^{\prime} \frac{i_{k}^{n}+i_{k}^{n-1}}{2}+L^{\prime} \frac{i_{k}^{n}-i_{k}^{n-1}}{\Delta t}+V s_{k}^{n}=E_{k}^{n}
$$

with

$$
\begin{aligned}
V s & {[(k-1 / 2) \Delta x, n \Delta t]=V s_{k}^{n} } \\
& =\int_{0}^{n \Delta t} \xi_{g}^{\prime}[n \Delta t-\tau] \frac{\partial i[(k-1 / 2) \Delta x, \tau]}{\partial \tau} d \tau .
\end{aligned}
$$

Using the trapezoidal method for solving the integral, $V s_{k}^{n}$ can be written as

$$
V s_{k}^{n}=\frac{1}{2} \sum_{m=0}^{n-1}\left\{\xi^{n-m-1}\left(i_{k}^{m+1}-i_{k}^{m}\right)+\xi^{n-m}\left(i_{k}^{m}-i_{k}^{m-1}\right)\right\} .
$$

Rearranging (A5), we get

$$
\begin{aligned}
V s_{k}^{n}= & \frac{1}{2} \xi^{n}\left(i_{k}^{0}-i_{k}^{-1}\right)+\sum_{m=1}^{n-1} \xi^{n-m}\left(i_{k}^{m}-i_{k}^{m-1}\right) \\
& +\frac{1}{2} \xi^{0}\left(i_{k}^{n}-i_{k}^{n-1}\right) .
\end{aligned}
$$

Introducing (A6) in (A4), we obtain

$$
\begin{aligned}
& \frac{v_{k+1}^{n}-v_{k}^{n}}{\Delta x}+R^{\prime} \frac{i_{k}^{n}+i_{k}^{n-1}}{2}+L^{\prime} \frac{i_{k}^{n}-i_{k}^{n-1}}{\Delta t} \\
& +\frac{1}{2} \xi^{0}\left(i_{k}^{n}-i_{k}^{n-1}\right)+\sum_{m=1}^{n-1} \xi^{n-m}\left(i_{k}^{m}-i_{k}^{j-m}\right)=E_{k}^{n} .
\end{aligned}
$$

The induced current can be expressed as

$$
\begin{aligned}
& i_{k}^{n}=\frac{1}{\left(\frac{L^{\prime}}{\Delta t}+\frac{R^{\prime}}{2}+\frac{\xi^{0}}{2}\right)}\left[E_{k}^{n}-\frac{v_{k+1}^{n}-v_{k}^{n}}{\Delta x}\right. \\
& \left.+\left(\frac{L^{\prime}}{\Delta t}-\frac{R^{\prime}}{2}+\frac{\xi^{0}}{2}\right) i_{k}^{n-1}-\sum_{j=1}^{n-1} \xi^{n-j}\left(i_{k}^{j}-i_{k}^{j-1}\right)\right] .
\end{aligned}
$$

Now, let us consider the point centered FDTD representation of (A2) for the node $((k-1) \Delta x,(n-1 / 2) \Delta t)$ :

$$
\begin{aligned}
\frac{i_{k}^{n-1}-i_{k-1}^{n-1}}{\Delta x}+G^{\prime} \frac{v_{k}^{n}+v_{k}^{n-1}}{2}+C^{\prime} \frac{v_{k}^{n}-v_{k}^{n-1}}{\Delta t} \\
+\sum_{j=1}^{n} \eta^{n-j}\left[v_{k}^{j}-v_{k}^{j-1}\right]=0 .
\end{aligned}
$$

After the similar mathematical developments as for (A4), we obtain:

$$
\begin{aligned}
& v_{k}^{n}=\frac{1}{\left(\frac{C^{\prime}}{\Delta t}+\frac{G^{\prime}}{2}+\frac{\eta^{0}}{2}\right)}\left[-\frac{i_{k}^{n-1}-i_{k-1}^{n-1}}{\Delta x}\right. \\
& \left.+\left(\frac{C^{\prime}}{\Delta t}-\frac{G^{\prime}}{2}+\frac{\eta^{0}}{2}\right) v_{k}^{n-1}-\sum_{j=1}^{n-1} \eta^{n-j}\left[v_{k}^{j}-v_{k}^{j-1}\right]\right] .
\end{aligned}
$$

The boundary conditions for the case of resistive terminations $R_{0}$ and $R_{L}$ (Fig. 11) are given by 


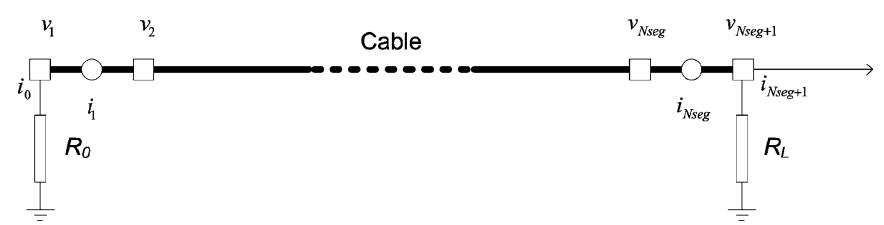

Fig. 11. Schematic representation of the spatial discretization along the cable with resistive terminations.

For $x=0$

$$
i_{0}^{n}=\frac{-v_{1}^{n}}{R_{0}}
$$

the current $i_{0}^{n}$ can be determined using a linear extrapolation:

$$
i_{0}^{n}=\frac{3 i_{1}^{n}-i_{2}^{n}}{2} .
$$

Now, let us write (A8) for the spatial node 1

$$
\begin{aligned}
& i_{1}^{n}=\frac{1}{\left(\frac{L^{\prime}}{\Delta t}+\frac{R^{\prime}}{2}+\frac{\xi^{0}}{2}\right)}\left[E_{1}^{n}-\frac{v_{2}^{n}-v_{1}^{n}}{\Delta x}\right. \\
& \left.+\left(\frac{L^{\prime}}{\Delta t}-\frac{R^{\prime}}{2}+\frac{\xi^{0}}{2}\right) i_{1}^{n-1}-\sum_{j=1}^{n-1} \xi^{n-j}\left(i_{1}^{j}-i_{1}^{j-1}\right)\right] .
\end{aligned}
$$

Combining (A11) and (A12)

$$
v_{1}^{n}=-R_{0} \frac{3 i_{1}^{n}-i_{2}^{n}}{2} .
$$

Introducing (A14) in (A13), we get

$$
\begin{aligned}
& i_{1}^{n}=\frac{1}{\left(\frac{L^{\prime}}{\Delta t}+\frac{R^{\prime}}{2}+\frac{\xi^{0}}{2}+\frac{3 R_{0}}{2 \Delta x}\right)}\left[E_{1}^{n}-\frac{v_{2}^{n}}{\Delta x}+\frac{R_{0}}{2 \Delta x} i_{2}^{n}\right. \\
& \left.+\left(\frac{L^{\prime}}{\Delta t}-\frac{R^{\prime}}{2}+\frac{\xi^{0}}{2}\right) i_{1}^{n-1}-\sum_{j=1}^{n-1} \xi^{n-j}\left(i_{1}^{j}-i_{1}^{j-1}\right)\right] .
\end{aligned}
$$

For $x=L$

$$
i_{N \operatorname{seg}+1}^{n}=\frac{v_{N \operatorname{seg}+1}^{n}}{R_{L}}
$$

the current $i_{N \text { seg }+1}^{n}$ can be determined using a linear extrapolation:

$$
i_{N \text { seg }+1}^{n}=\frac{3 i_{N \text { seg }}^{n}-i_{N \text { seg }-1}^{n}}{2} .
$$

Using the expression (A8) written for the spatial node $N_{\text {seg }}$

$$
\begin{aligned}
i_{N \text { seg }}^{n}= & \frac{1}{\left(\frac{L^{\prime}}{\Delta t}+\frac{R^{\prime}}{2}+\frac{\xi^{0}}{2}\right)}\left[E_{N \text { seg }}^{n}-\frac{v_{N \text { seg }+1}^{n}-v_{N \text { seg }}^{n}}{\Delta x}\right. \\
& +\left(\frac{L^{\prime}}{\Delta t}-\frac{R^{\prime}}{2}+\frac{\xi^{0}}{2}\right) i_{N \text { seg }}^{n-1} \\
& \left.-\sum_{j=1}^{n-1} \xi^{n-j}\left(i_{N \text { seg }}^{j}-i_{N \text { seg }}^{j-1}\right)\right]
\end{aligned}
$$

Combining (A16) and (A17) yields

$$
v_{N \text { seg }+1}^{n}=R_{L} \frac{3 i_{N \text { seg }}^{n}-i_{N \text { seg }-1}^{n}}{2}
$$

Introducing (A19) into (A18) yields the sought expression

$$
\begin{aligned}
i_{N \text { seg }}^{n}= & \frac{1}{\left(\frac{L^{\prime}}{\Delta t}+\frac{R^{\prime}}{2}+\frac{\xi^{0}}{2}+\frac{3 R_{L}}{2 \Delta x}\right)}\left[E_{N \text { seg }}^{n}+\frac{R_{L}}{2 \Delta x} i_{N \text { seg }-1}^{n}\right. \\
& +\frac{v_{N \text { seg }}^{n}+\left(\frac{L^{\prime}}{\Delta t}-\frac{R^{\prime}}{2}+\frac{\xi^{0}}{2}\right) i_{N \text { seg }}^{n-1}}{} \\
& \left.-\sum_{j=1}^{n-1} \xi^{n-j}\left(i_{N \text { seg }}^{j}-i_{N \text { seg }}^{j-1}\right)\right]
\end{aligned}
$$

\section{REFERENCES}

[1] F. M. Tesche, A. W. Kälin, B. Brändly, B. Reusser, M. Ianoz, D. Tabara, and P. Zweiacker, "Estimates of lightning-induced voltage stresses within buried shielded conduits," IEEE Trans. Electromagn. Compat., vol. 40, pp. 492-504, 1998.

[2] A. Galvan and G. V. Cooray, "Lightning induced voltages on bare and insulated buried cables," in Proc. 13th Zurich Int. Symp. on EMC, Zurich, 1999.

[3] A. Baños, Dipole Radiation in the Presence of a Conducting Half-Space. Oxford: Pergamon Press, 1966.

[4] V. Cooray, "Underground electromagnetic fields generated by the return strokes of lightning flashes," IEEE Trans. Electromagn. Compat., vol. 43, pp. 75-84, 2001

[5] P. Parhami, Y. Rahmat-Samii, and R. Mittra, "An efficient approach for evaluating Sommerfeld integrals encountered in the problem of a current element radiating over lossy ground," IEEE Trans. Antennas Propagat., vol. 28, pp. 100-104, 1980.

[6] V. W. Hansen, Numerical Solutions of Antennas in Layered Media. New York: Wiley, 1989.

[7] F. Rachidi, C. A. Nucci, M. Ianoz, and C. Mazzetti, "Influence of a lossy ground on lightning-induced voltages on overhead lines," IEEE Trans. Electromagn. Compat., vol. 38, pp. 250-264, 1996.

[8] V. Cooray, "Horizontal fields generated by return strokes," Radio Sci., vol. 27 , pp. 529-537, 1992.

[9] M. Rubinstein, "An approximate formula for the calculation of the horizontal electric field from lightning at close, intermediate, and long range," IEEE Trans. Electromagn. Compat., vol. 38, pp. 531-535, 1996.

[10] A. Zeddam, "Couplage d'une onde electromagnetique rayonnee par une décharge orageuse à un câble de telécommunications," Ph.D. dissertation, Université des Sciences et Techniques de Lille, France, 1988.

[11] E. F. Vance, Coupling with Shielded Cables. New York: Wiley, 1978.

[12] S. Ramo, J. R. Whinnery, and T. Van Duzer, Fields and Waves in Communications Electronics. New York: Wiley, 1994.

[13] F. M. Tesche, M. Ianoz, and T. Karlsson, EMC Analysis Methods and Computational Models. New York: Wiley, 1997.

[14] F. Pollaczek, "Über das feld einer unendlich langen wechsel stromdurchflossenen Einfachleitung," Electrishe Nachrichten Technik, vol. 3 , pp. 339-360, 1926.

[15] E. D. Sunde, Earth Conduction Effects in Transmission Systems. New York: Dover, 1968.

[16] H. W. Dommel, "Electromagnetic Transients Program (EMTP theory book) Bonneville Power Administration," 1986.

[17] O. Saad, G. Gaba, and M. Giroux, "A closed-form approximation for ground return impedance of underground cables," IEEE Trans. Power Del., vol. 11, pp. 1536-1545, 1996.

[18] G. E. Bridges, "Fields generated by bare and insulated cables buried in a lossy half-space," IEEE Trans. Geosci. Remote Sens., vol. 30, 1992.

[19] F. Rachidi, S. L. Loyka, C. A. Nucci, and M. Ianoz, "A new expression for the ground transient resistance matrix elements of multiconductor overhead transmission lines," Electrical Power Syst. Res., vol. 65, pp. 4146, 2003. 
[20] C. A. Nucci and F. Rachidi, "Interaction of electromagnetic fields generated by lightning with overhead electrical networks," in The Lightning Flash, G. V. Cooray, Ed., London, U.K.: IEE, 2003.

[21] A. Taflove, Computational Electrodynamics: The Finite-Difference Time Domain Method. Boston, MA: Artech House, 1995.

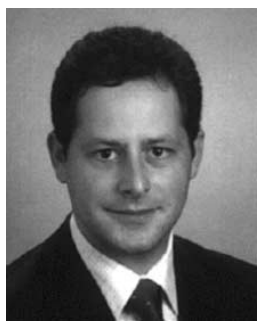

Emanuel Petrache (S'02-M'04) was born in Constanta, Romania, in 1975. He received the M.S. degree in electrical engineering from the University Politehnica of Bucharest, Romania, in 1998, and the $\mathrm{Ph} . \mathrm{D}$. degree from the Swiss Federal Institute of Technology, Lausanne, in 2004.

Currently, he is with the Lightning Studies Group of the University of Toronto, Canada. He is author or coauthor of many scientific papers presented at international conferences. His research interests include numerical computation of electromagnetic fields, lightning, and EMP interaction with transmission lines.

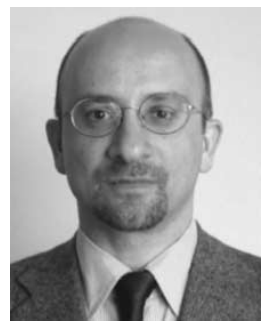

Carlo Alberto Nucci (M'91-SM'02) was born in Bologna, Italy, in 1956. He received the engineering degree with honors in electrical engineering in 1982 from the University of Bologna, Italy.

He joined the same university in 1982 as a researcher in the Power Electrical Engineering Institute, became an Associate Professor in 1992, and a Full Professor in Power Systems in 2000. He is author or coauthor of more than 160 scientific papers published in reviewed journals or presented at international conferences. He is member of the IEEE working group "Lightning Performance of Distribution Lines," the CIGRE Working groups C4.4.01 "Lightning" (of which he is also convener), and C4.4.07 "Power Quality Indices and Objectives." His research interests concern power systems transients and dynamics, with particular reference to lightning impact on power lines, voltage collapse, power station simulators, and the study of power components including medium voltage capacitors and traction batteries.

Mr. Nucci is the Chair of the Central \& South Italy/North Italy IEEE PES Joint Chapter PE31 in Region 8.

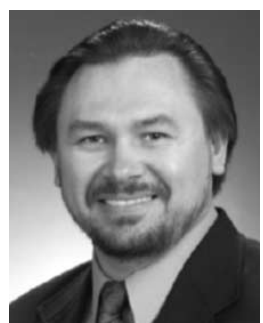

Vladimir A. Rakov (SM'96-F'03) received the M.S. and $\mathrm{Ph} . \mathrm{D}$. degrees in electrical engineering from Tomsk Polytechnical University (Tomsk Polytechnic), Russia in 1977 and 1983, respectively.

From 1977 to 1979 he was an Assistant Professor of Electrical Engineering at Tomsk Polytechnic. In 1978 he became involved in lightning research at the High Voltage Research Institute, a division of Tomsk Polytechnic, where from 1984 to 1994 he held the position of Director of the Lightning Research Laboratory. He is presently a Professor in the Department of Electrical and Computer Engineering at the University of Florida. He is the author or coauthor of over 30 patents, one book, and over 300 papers and technical reports on various aspects of lightning.

Dr. Rakov is Chairman of the Technical Committee on Lightning of the biennial International Zurich Symposium on Electromagnetic Compatibility, and former chairman of the AGU Committee on Atmospheric and Space Electricity. He is a Member of SAE, and is a Fellow of the American Meteorological Society.

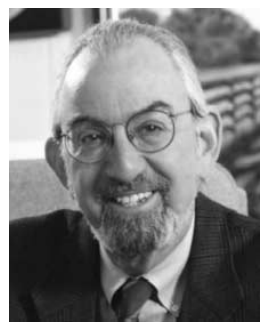

Martin A. Uman (SM'73-F'88) received the Ph.D. degree from Princeton University, Princeton, NJ, in 1961.

He was an Associate Professor of Electrical Engineering at the University of Arizona, Tucson, from 1961 to 1964 . He joined the University of Florida's (UF) faculty in 1971 after working for seven years as a Fellow Physicist at Westinghouse Research Labs, Pittsburgh, PA. He cofounded and served as President of Lightning Location and Protection Inc. (LLP), Tucson, AZ, from 1975 to 1985 . He was the Professor and Chair of the UF Department of Electrical and Computer Engineering, from 1990-2003, and is now a Distinguished Professor. He has written four books on the subject of lightning, as well as a book on plasma physics, ten book chapters and encyclopedia articles on lightning, and has published over 170 journal papers in reviewed journals. He holds five patents, four in the area of lightning detection.

Dr. Uman is the recipient of the 1996 IEEE Heinrich Hertz Medal for outstanding contributions to the understanding of lightning electromagnetics and its application to lightning detection and protection," and the 2001 AGU John Adam Fleming Medal for original research and technical leadership in geomagnetism, atmospheric electricity, space science, aeronomy, and related sciences: for outstanding contribution to the description and understanding of electricity and magnetism of the Earth and its atmosphere." He is a Fellow of the American Geophysical Union (AGU) and the American Meteorological Society (AMS). systems dynamics, power system protection and electric vehicle batteries. He is the author or coauthor of some 50 scientific papers presented at international conferences or published in reviewed journals.
Mario Paolone was born in Campobasso, Italy, in neering and received the Ph.D. degree in electrical engineering from the University of Bologna, Bologna, He is Assistant Professor of electrical power sysat the University of Bologna and is curre working within the Power Systems Group of the same University. His research interests are power system transients, with particular reference to NEMP and LEMP interaction with electrical networks, power 